\title{
PENGEMBANGAN ATBM (ALAT TENUN BUKAN MESIN) MENGGUNAKAN SISTEM DOBBY ELEKTRONIK
}

\author{
DEVELOPING OF ATBM USING ELECTRONIC \\ DOBBY SYSTEM \\ Ferry Guswandhi, Rizal Fahruroji \\ Balai Besar Tekstil, Jalan Jendral Ahmad Yani No. 390 Bandung \\ E-mail : texirdti@bdg.centrin.net.id
}

Tanggal diterima: 28 Agustus 2017, direvisi: 19 Juli 2018, disetujui terbit: 20 Juli 2018

\begin{abstract}
ABSTRAK
Salah satu tahapan dalam pertenunan ATBM dobby ialah pembuatan desain tenun (gambar desain, penyusunan kartu dobby, pemasangan kartu pada perangkat dobby). Tahapan ini relatif lama terutama untuk desain yang rumit. Penelitian pembuatan ATBM dobby elektronik diharapkan dapat mempersingkat proses desain kain tenun ATBM. Penelitian meliputi pembuatan rangka ATBM, menyusun perangkat dobby elektronik, pembuatan software desain, pembuatan sistem kontrol dobby elektronik, persiapan pertenunan, dan pengujian ATBM (proses tenun). Hasil pengujian ATBM dobby elektronik dibandingkan dengan ATBM dobby mekanik dalam hal pembuatan kain tenun menunjukkan bahwa ATBM dobby elektronik unggul dalam hal pembuatan desain, mekanisasi proses tenun (pembukaan mulut lusi, penguluran benang lusi dan penggulungan kain), dan kemudahan operasional tenun berkat penerapan teknologi elektronik.
\end{abstract}

Kata kunci : pertenunan, ATBM, sistem dobby, software desain, sistem kontrol elektronik

\section{ABSTRACT}

One stage in weaving dobbyhandloom is making woven design (pattern making, arrange dobby card, set up the card on dobby device). This relatively long especially for complicated designs. The research of manufacture of electronic dobby handloom is expected to shorten the design process of handloom woven fabric. The research includes designing of ATBM frame, arranging the electronic dobby device, making ofsoftware design, the manufacture of electronic dobby system, weaving preparation, and handloom testing (weaving process). Handloomof electronic dobby test results compared to mechanics dobbyhandloom in terms of fabrics manufacture shows that electronics dobbyhandloom excel in terms of making design, mechanization of weaving process (shedding,let-off andfabric take up), and ease of operation of weaving thanks to the application of electronic technology.

Keywords : weaving, handloom, dobby system, software design, electronic control system

\section{PENDAHULUAN}

Kain tenun tradisional yang dihasilkan beberapa daerah di Indonesia pada umumnya dibuat secara manual menggunakan Alat Tenun Bukan Mesin (ATBM) atau menggunakan gedogan dimana teknologinya masih sangat sederhana. Penggunaan ATBM maupun gedogan dalam memproduksi kain tenun relatif lama, semakin variatif desain yang ingin dihasilkan maka semakin banyak pula waktu yang dibutuhkan, baik saat proses tenun atau persiapan pertenunannya. ${ }^{1}$
Penelitian ini bertujuan mengembangkan ATBM dengan menggunakan sistem dobby elektronik. Dalam rancang bangun ini, beberapa fungsi tenun pada ATBM diganti mekanisme kerjanya secara elektronik, diantaranya fungsi dobby, penguluran benang lusi dan penggulungan kain. Kain yang dihasilkan tetap memiliki ciri dan karakteristik hasil tenun ATBM. Dengan dikembangkannya ATBM dobby elektronik tersebut diharapkan proses pembentukan desain menjadi lebih cepat dan dapat digunakan kembali 
dengan memanggil data desain yang diinginkan karena data desain sudah tersimpan pada database komputer.

Totok Wartiono pada 2008 telah mengembangkan ATBM dengan pengendali PLC (Programmable Logic Control) bertujuan untuk mengembangkan tenun. ${ }^{2}$ Pada penelitian tersebut semua gerakan pertenunan dikontrol oleh PLC untuk memudahkan penenun dalam mengoperasikan ATBM.

Pada penelitian ini difokuskan pada pengembangan alat pembentukan desain, yaitu dobby, dengan mengubah kinerjanya dari semula mekanik menjadi elektronik. Dobby merupakan perangkat alat/mesin tenun yang berfungsi mengangkat kamran (heald frame) melalui skema kartu dobby, hook dan tali sehingga sebagian kamran naik hingga terbentuk anyaman tenun. ${ }^{3}$ Pada ATBM yang menggunakan dobby secara mekanik, proses persiapan untuk membuat desain relatif lama hal ini dikarenakan adanya proses pemasangan paku pada kartudobby yang memerlukan ketelitian dan tingkat kesulitan tinggi terutama untuk desain yang lebih variatif.

Perubahan kinerja dobbydari mekanik menjadi elektronik diatur oleh suatu sistem kontrol elektronik. Sistem kontrol elektronik adalah proses pengaturan ataupun pengendalian terhadap satu atau beberapa besaran (variabel, parameter) sehingga berada pada suatu harga atau dalam suatu rangkuman harga (range) tertentu. ${ }^{4}$ Di dalam dunia industri, dituntut suatu proses kerja yang aman dan berefisiensi tinggi untuk menghasilkan produk dengan kualitas dan kuantitas yang baik serta dengan waktu yang telah ditentukan. Otomatisasi sangat membantu dalam hal kelancaran operasional, keamanan (investasi, lingkungan), ekonomi (biaya produksi), mutu produk, dll. ${ }^{5}$

\section{METODOLOGI PENELITIAN}

Penelitian dilakukan dengan menganalisis tiga faktor utama dalam pembuatan ATBM dobby elektronik. Tiga faktor tersebut yaitu desain rangka ATBM, desain sistem dobby elektronik, desain sistem kontrol elektronik berbasis relay dan software desain.

\section{Desain Rangka ATBM Dobby Elektronik}

Rangka ATBM yang dibuat disesuaikan dengan sistem dobby elektronik yang dikembangkan. Pada ATBM dobby mekanik, posisi dobby umunya berada diatas. Pada ATBM dobby elektronik posisi dobby berada dibawah.

\section{Desain Sistem Dobby Elektronik}

Dobbyelektronik merupakan penghubung antara sistem elektronik dan tali kamran.Sistem elektromagnet pada perancangan dobby elektronik berperan penting sebagai penghubung antara sistem elektronik dan tali kamran. ${ }^{6}$ Sistem elektromagnet pada dobby elektronik berperan terhadap pergerakan hookdobbyjuga terhadap kualitas kain tenun. Perancangan sistem elektromagnet yang kurang optimal akan berakibat terhadap kurangnya tegangan benang lusi sehingga benang menjadi putus dan kualitas kain tenun berkurang.

Dobby elektronikmenjadikan proses tenun lebih efisien dan mengurangi keterlibatan manusia terhadap kinerja mesin. ${ }^{7}$ Dobbyelektronik menjadikan ATBM lebih fungsional.ATBM dobby elektronik terdiri dari 8 solenoid yang berfungsi mengangkat kamran.

\section{Desain Sistem Kontrol Elektronik}

Sistem kontrol diperlukan untuk mengendalikan kinerja dobby elektronik agar lebih optimal. Input berupa anyaman tenun secara digital diatur melalui injakan sehingga terjadi perpindahan desain setiap pick-nya. Input diteruskan melalui sistem elektronik untuk menggerakkan motor sesuai desain anyaman. Motor bergerak maju-mundur berkat adanya relay.Relay adalah Saklar (Switch) yang dioperasikan secara listrik dan merupakan komponen electromechanical (elektro-mekanikal) yang terdiri dari 2 bagian utama yakni elektromagnet (Coil) dan mekanikal (seperangkat kontak saklar/switch). ${ }^{8}$ Relay menggunakan prinsip elektromagnetik untuk menggerakkan kontak saklar sehingga dengan arus listrik yang kecil (low power) dapat menghantarkan listrik yang bertegangan lebih tinggi. ${ }^{9}$ Tahapan alur sistem elektronik pada ATBM dobby elektronik seperti terlihat pada Gambar 1. Sedangkan ntuk mengetahui hubungan antar komponen elektronik maka disusunlah skema diagram blok seperti pada Gambar 2.

\section{Bahan Baku Benang}

Benang yang digunakan yaitu benang kapas dengan nomor benang $\mathrm{Ne}_{1} 30$ untuk lusi dan pakan.

\section{Penghanian}

Penghanian ialah mempersiapkan benang lusi pada beam lusi/tenun dengan jumlah helai benang, 
panjang dan lebar tertentu berdasarkan rencana tenun $^{10}$, sehingga siap untuk ditenun.

Lebar kain $\quad: 60 \mathrm{~cm}$

Jumlah benang lusi $\quad: 1100$ helai

Panjang benang lusi $\quad: 30$ meter

Nomor sisir tenun $\quad: 30$

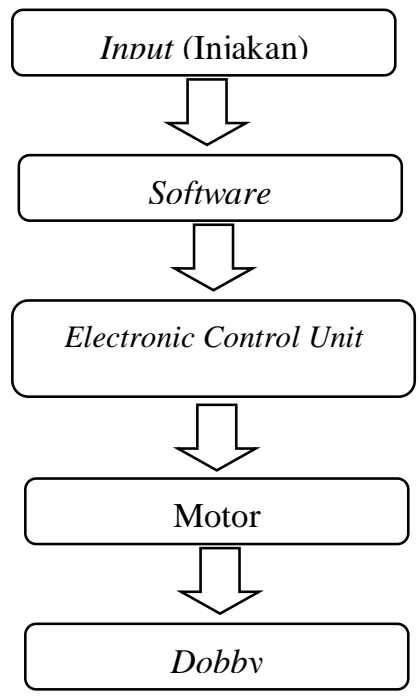

Gambar 1. Alur Sistem Elektronik

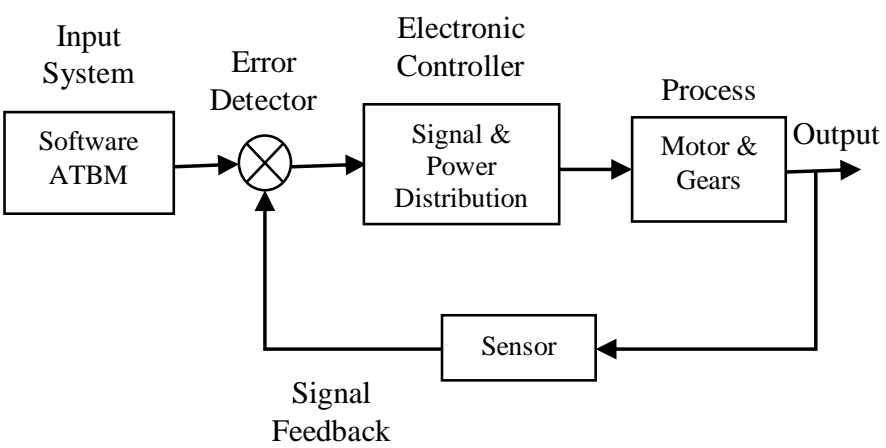

Gambar 2. Diagram Blok Sistem Kontrol Elektronik

\section{HASIL DAN PEMBAHASAN}

Desain Rangka ATBM Dobby Elektronik

Rangka ATBM dobby elektronik dirancang dengan menyesuaikan perangkat-perangkat tambahan yang terpasang pada ATBM tersebut. Perangkat tambahan tersebut ialah sistem kontrol elektronik, perangkat dobby elektronik dan komputer. Hasil desain rangka ATBM dobby elektronik dapat dilihat seperti pada Gambar 3.

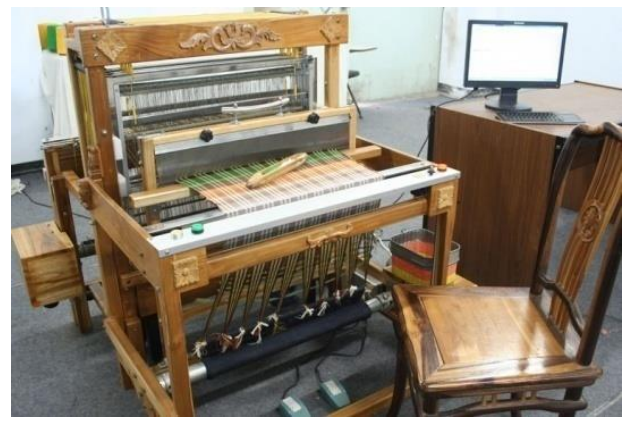

Gambar 3. ATBM Dobby Elektronik

Rangka ATBM dibuat dari kayu jati didasarkan atas karakteristiknya yang stabil, kuat dan tahan lama membuat kayu ini menjadi pilihan utama sebagai material bahan rangka ATBM. Kayu jati juga terbukti tahan terhadap jamur, rayap dan serangga lainnya karena kandungan minyak di dalam kayu itu sendiri. ${ }^{11}$ Tidak ada kayu lain yang memberikan kualitas dan penampilan sebanding dengan kayu jati.

Rangka ATBM dibuat dari kayu jati dengan dimensi :

$$
\begin{array}{ll}
\text { Panjang } & : 110 \mathrm{~cm} \\
\text { Lebar } & : 92 \mathrm{~cm} \\
\text { Tinggi } & : 115 \mathrm{~cm} \\
\text { Jumlah kamran } & : 8
\end{array}
$$

Dimensi ATBM ini memiliki lebar sisir tenun 65 $\mathrm{cm}$, sementara untuk lebar sisir efektif $60 \mathrm{~cm}$. Lebar sisir efektif ialah lebar sisir yang terisi oleh benang lusi. Rangka ATBM dobby elektronik dapat dilihat pada Gambar 4.

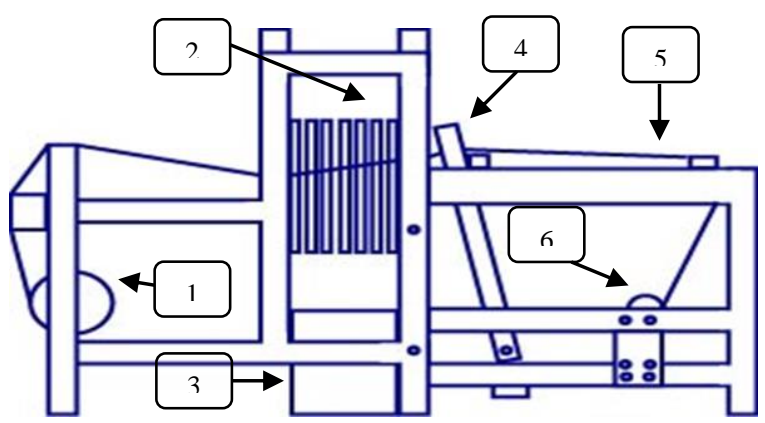

Gambar 4. Rangka ATBM Dobby Elektronik (Tampak Samping)

Keterangan :

1. Beam lusi

2. Kamran

3. Perangkat dobby

4. Lade

5. Kain tenun

6. Beam kain 


\section{Desain Sistem Kontrol Elektronik}

Relay merupakan salah satu sistem kontrol elektronik yang banyak dikembangkan dan dapat terintegrasi dengan sistem IT, komputer dan permesinan. ${ }^{12}$ Sistem kontrol elektronik berbasis relay ini dikembangkan untuk menghubungkan perintah kerja dari komputer dengan perangkat dobby elektronik. Sistem kontrol elektronik dapat dilihat seperti Gambar 5.

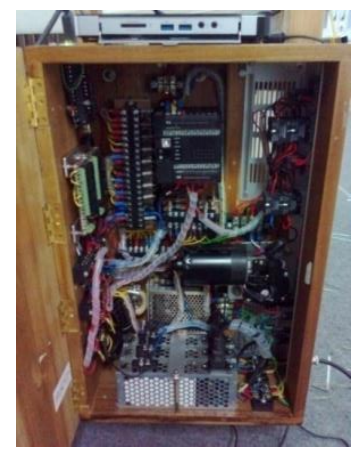

Gambar 5. Sistem Kontrol Elektronik

Perintah kerja dari komputer yaitu berupa desain tenun yang digambar pada software $C A D$ (Computer Aided Design). Software CAD merupakan suatusistem yang digunakan untuk membuat model digital untuk memudahkan dalam proses industri. ${ }^{13}$ Software desain ini merupakan rancangan sendiri dengan nama software ATBM. Software ini dirancang untuk memudahkan penenun dalam membuat desain tenun. Tampilan software ATBM dapat dilihat pada Gambar 6.

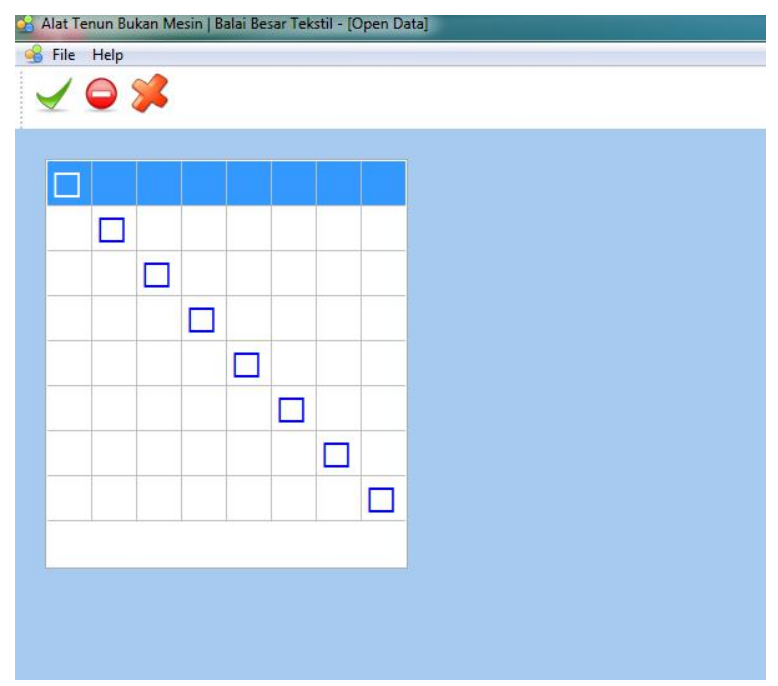

Gambar 6. Software Desain ATBM

Perintah kerja ATBM diawali dari desain tenunyang terdapat pada software desain ATBM.
Pada tampilan software diatas, kotak biru menandakan kamran naik dan sebaliknya. Susunan software ke arah kolom horizontal menunjukkan jumlah kamran (8 unit), sedangkan setiap baris ke arah vertikal menunjukkan jumlah benang pakan setiap repeat-nya.

Melalui injakan elektronik, perintah akan disalurkan dari software, electronic control unitdan perangkat dobby elektronik hingga kamran naik sesuai dengan desain tenun. Tanda kotak pada tampilan software ATBM diatas (Gambar 6) menunjukkan bahwa kamran naik.

\section{Desain Sistem Dobby Elektronik}

Perangkat dobby elektronik terdiri dari motor, solenoid, hook bar, rantai dan tali yang terhubung dengan kamran. Skema perangkat dobby elektronik dapat dilihat pada Gambar 7.

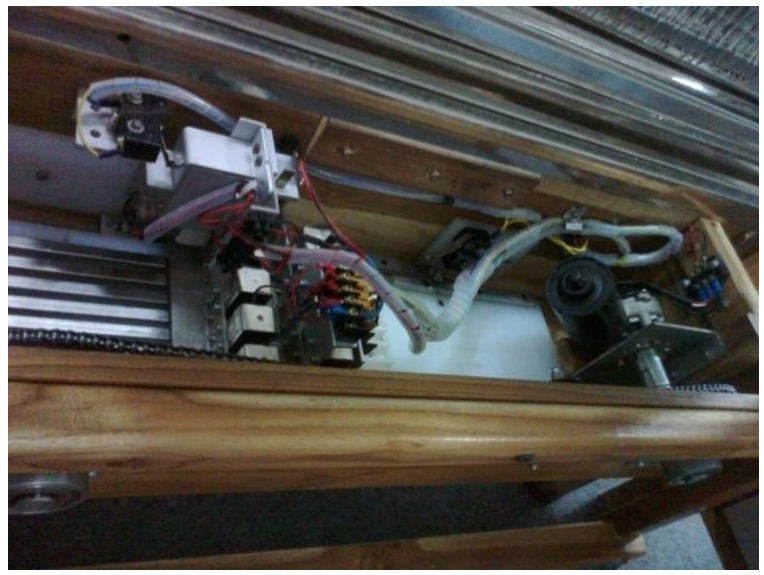

Gambar 7. Perangkat Dobby Elektronik

Prinsip kerja dari perangkat dobby elektronik ialah arus perintah dari electronic control unit diteruskan kepada perangkat dobby sehingga solenoid akan menempel pada hook dobby.Kemudian dengan adanya putaran motor,solenoidakan menarik hook yang terhubung dengan kamran sehingga kamran terangkat. Skema perangkat dobby elektronik dapat dilihat pada Gambar 8.

Solenoid telah banyak digunakan secara luas pada perangkat elektromagnet karena mempunyai struktur yang sederhana dan besaran gaya elektromagnet dapat dikontrol dengan mengubah arus listrik yang diberikan pada solenoid. ${ }^{14}$ 


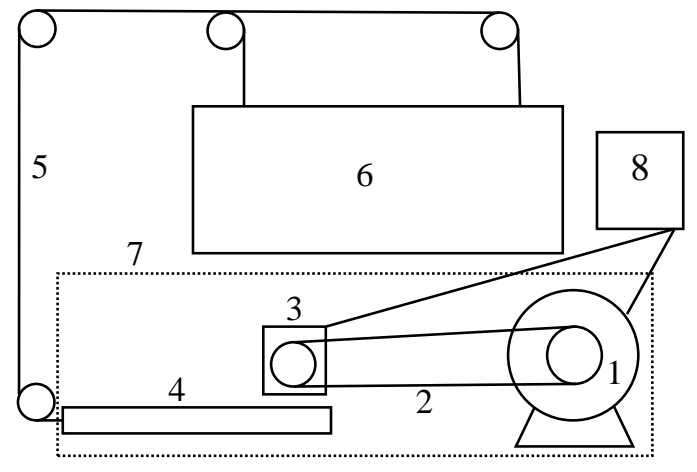

Gambar 8. Skema Perangkat Dobby Elektronik (Tampak Depan)

Keterangan :

1. Motor

2. Rantai

3. Solenoid

4. Hook bar

5. Tali kamran

6. Kamran

7. Perangkat dobbyelektronik

8. Electronic control unit

Hasil pengujian ATBM dobby elektronik

Pengujian dilakukan dengan proses pertenunan pada ATBM berdasarkan benang lusi yang telah disiapkan pada proses hani. Beberapa hal yang menjadi parameter dalam pengujian ATBM ini ialah:

1. Sistem kerja dobby elektronik

2. Pembukaan mulut lusi (shedding), yaitu proses menaikkan atau menurunkan sebagian benang lusi. Proses naik kamran perlu diperiksa apakah kurang naik/tidak terutama untuk kamran paling belakang, kemudian besaran tegangan lusi juga perlu diperhatikan. Mulut lusi yang bersih berarti pengangkatan lusi relatif rata dan saat teropong lewat tidak mengalami kesulitan yang berarti seperti misalnya teropong menabrak benang lusi.

3. Peluncuran benang pakan (Filling), yaitu proses memasukkan benang pakan ke dalam mulut lusi. Kelancaran proses memasukan benang pakan bergantung kepada mulut lusi yang terbentuk.

4. Pengetekan benang pakan, yaitu proses merapatkan benang pakan.

5. Penguluran benang lusi dari lalatan (beam) tenun.

6. Penggulungan kain pada rol kain.

Berikut adalah hasil uji kinerja ATBM dobby elektronik dapat dilihat pada Tabel 1 dibawah ini.

Tabel 1. Hasil Unjuk Kinerja ATBM Dobby Elektronik

\begin{tabular}{|c|c|c|c|}
\hline No & Parameter & Hasil Uji & Tindakan Perbaikan \\
\hline 1 & $\begin{array}{l}\text { Pembukaan mulut lusi } \\
\text { termasuk juga } \\
\text { tegangan benang lusi. }\end{array}$ & $\begin{array}{c}\text { Kamran no } 6,7,8 \\
\text { kurang naik }\end{array}$ & $\begin{array}{l}\text { Simpul tali kamran untuk ketiga kamran } \\
\text { dinaikkan }\end{array}$ \\
\hline 2 & $\begin{array}{l}\text { Peluncuran benang } \\
\text { pakan }\end{array}$ & Baik & - \\
\hline 3 & $\begin{array}{l}\text { Penguluran benang } \\
\text { lusi }\end{array}$ & Baik & - \\
\hline 4 & Penggulungan kain & Baik & - \\
\hline 5 & $\begin{array}{l}\text { Komunikasi antara } \\
\text { software desain, } \\
\text { sistem kontrol ATBM } \\
\text { dan dobby elektronik }\end{array}$ & $\begin{array}{c}\text { Terkadang } \\
\text { terputus }\end{array}$ & $\begin{array}{l}\text { 1. Disusun standar prosedur kerja untuk } \\
\text { operasional ATBM, agar penenun tidak salah } \\
\text { operasi yang menyebabkan terganggunya } \\
\text { komunikasi antara ATBM dan software } \\
\text { desain } \\
\text { 2. Periksa perangkat elektronik terutama relay } \\
\text { dan sekring (fuse) }\end{array}$ \\
\hline
\end{tabular}


Hal yang menjadi perhatian pada unjuk kinerja ATBM dobby elektronik ialah komunikasi yang sering terputus antara software dan electronic control unit, hal ini menyebabkan kinerja perangkat dobby elektronik terganggu (solenoid jammed). Hal yang dilakukan jika terjadi hal demikian ialah :

1. Restart sistem

2. Sikring (fuse) diperiksa, apakah putus atau tidak

3. Relay diperiksa, apakah putus atau tidak.

\section{Hasil Pengujian Kain}

Kain tenun hasil ATBM dobby elektronik dapat digunakan sebagai bahan pakaian (sandang) dan non sandang. Pada Gambar 9 berikut ini merupakan kain tenun hasil ATBM dobby elektronik yang digunakan sebagai taplak meja.

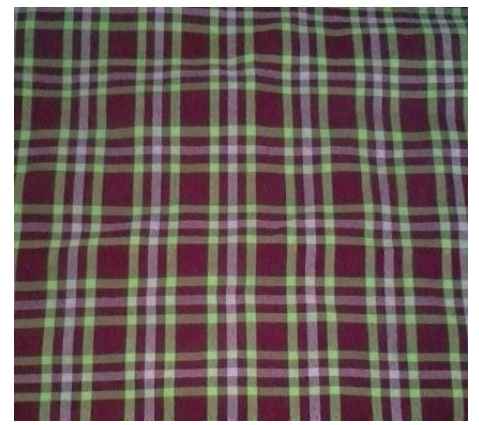

Gambar 9. Kain Hasil ATBM Dobby Elektronik

Sedangkan untuk kain sandang (pakaian) harus melalui berbagai uji agar kain tersebut siap digunakan sebagai bahan pakaian. Hasil pengujian kain tenun ATBM dobby elektronik dapat dilihat pada Tabel 2.

Tabel 2. Hasil Uji Fisika Kain Tenun ATBM Dobby Elektronik*)

\begin{tabular}{|c|l|c|}
\hline No & \multicolumn{1}{|c|}{ Jenis Uji } & Hasil Uji \\
\hline 1 & Lebar kain, m (inci) & $0,6(23,6)$ \\
\hline 2 & Berat Kain g/m ${ }^{2}(\mathrm{~g} / \mathrm{m})$ & $112,7(120,1)$ \\
\hline 3 & Konstruksi kain : & $18(46)$ \\
& 1. Tetal lusi, hl/cm (hl/inci) & $16(41)$ \\
& 2. Tetal pakan, $\mathrm{hl} / \mathrm{cm}(\mathrm{hl} / \mathrm{inci})$ & 30 \\
& 3. Nomor benang lusi, Ne & \\
& 4. Nomor benang pakan, Ne & \\
& 5. Anyaman & 30 \\
\hline 4 & Kekuatan tarik : & Keper \\
& 1. Arah lusi, N (kg) & $245,3(24,5)$ \\
& 2. Arah pakan, N (kg) & $271,2(27,2)$ \\
\hline 5 & Mulur : & 18,0 \\
& 1. Arah lusi, \% & 8,0 \\
\hline 6 & 2. Arah pakan, \% & \\
& Kekuatan sobek Elemendorf: & $48,1(4,8)$ \\
& 1. Arah lusi, N (kg) & $49,2(4,9)$ \\
\hline 7 & 2. Arah pakan, N (kg) & 4 \\
\hline 8 & Pilling box 3 jam & 10000 \\
\hline & gosok martindale s/d putus, $\Sigma$ & \\
\hline \multirow{2}{*}{ gosokan } & & \\
\hline
\end{tabular}

*) : Hasil uji berdasarkan SNI 0051:2008, Persyaratan Kain Tenun Untuk Kemeja. ${ }^{15}$

Kain tenun ATBM dobby elektronik yang dihasilkan memiliki lebar kain $60 \mathrm{~cm}$ dan panjang kain $30 \mathrm{~m}$. Kekuatan tarik kain/inci ialah 245,3 N atau 24,5kg (arah lusi) dan 271,2 $\mathrm{N}$ atau $27,2 \mathrm{~kg}$ (arah pakan). Pada SNI 0051:2008, persyaratan minimum untuk kekuatan tarik ialah 107,9 $\mathrm{N}$ atau 11 kg sehingga kain ATBM ini masih masuk dalam standar SNI.

Kualitas kekuatan sobek kain ATBM ini ialah $48,1 \mathrm{~N}$ atau 4,8 $\mathrm{kg}$ (arah lusi) dan 49,2 $\mathrm{N}$ atau $4,9 \mathrm{~kg}$ (arah pakan). Standar SNI 0051:2008 untuk kekuatan sobek ialah minimum $6,9 \mathrm{~N}(0,7 \mathrm{~kg})$ sehingga kain ATBM ini masih masuk dalam standar SNI.

Anyaman kain adalah keper. Anyaman keper merupakan anyaman dasar yang dapat dibuat pada ATBM dobby. Keper adalah anyaman yang dapat merupakan garis-garismiring pada permukaan kain, kemiringan dapat ke arah kiri (keper kiri) atau kanan (keper kanan). ${ }^{16}$ Contoh kain dengan anyaman keper salah satunya ialah kain denim (jeans).

\section{Perbandingan ATBM Dobby Mekanik dan ATBM Dobby Elektronik}

Perbandingan ATBM dobby mekanik dan dobby elektronik meliputi pembuatan desain tenun (rencana desain, gambar desain dan penyusunan kartu dobby serta pemasangan kartu dobby di ATBM) dan gerakan dasar pertenunan. Seperti dijelaskan pada Tabel 3.

ATBM dobby elektronik memiliki keunggulan dalam bidang persiapan desain tenun. Persiapan desain merupakan hal penting dalam pertenunan dobbydan rawan terjadi kesalahan. Persiapan desain tenun meliputi rencana desain, gambar desain dan penyusunan kartu dobby serta pemasangan kartu dobby di ATBM. ${ }^{17}$ Dengan diubah secara elektronik maka proses ini menjadi mudah bagi penenun, dan penenun dapat secara mudah memeriksa jika terjadi kesalahan desain tenun atau anyaman.

Keunggulan lainnya yaitu kemudahan dalam pengaturan tegangan benang lusi. Tegangan benang lusi dalam pertenunan berpengaruh terhadap kelancaran proses tenun. ${ }^{18}$ Tegangan benang lusi dipengaruhi beberapa faktor berikut ini

1. Kualitas benang

2. Proses penghanian

3. Sistem pengatur tegangan benang lusi pada ATBM/mesin tenun

Kualitas benang dan penghanian merupakan faktor diluar proses tenun, baik ATBM maupun mesin tenun. Kualitas benang sangat berpengaruh terhadap proses tenun. Pemilihan benang yang tepat akan meningkatkan efisiensi proses tenun dan 
mengurangi waktu berhenti mesin (stoppage). ${ }^{19}$ Penghanian merupakan proses persiapan pertenunan yang memiliki peran vital dalam proses pertenunan terutama mengenai tegangan benang.Faktor proses penghanian yang sangat penting yaitu keseragaman tegangan benang dari creel hingga tambur, jenis dan nomor benang yang sama serta kekerasan gulungan benang lusi pada beam tenun. ${ }^{20}$

Tabel 3. Perbandingan ATBM Dobby Mekanik dan ATBM Dobby Elektronik

\begin{tabular}{|c|c|c|c|}
\hline No. & Parameter & $\begin{array}{c}\text { ATBM Dobby } \\
\text { Mekanik }\end{array}$ & $\begin{array}{c}\text { ATBM Dobby } \\
\text { Elektronik }\end{array}$ \\
\hline 1 & $\begin{array}{l}\text { Pembuatan } \\
\text { desain tenun }\end{array}$ & $\begin{array}{l}\text { Menggunakan } \\
\text { kertas desain }\end{array}$ & $\begin{array}{c}\text { Dilakukan di } \\
\text { komputer } \\
\text { dengan software } \\
\text { desain }\end{array}$ \\
\hline 2 & $\begin{array}{l}\text { Penyusunan } \\
\text { paku pada } \\
\text { kartu dobby } \\
\text { (untuk motif } \\
\text { diamond) }\end{array}$ & $\begin{array}{c}\text { Dilakukan } 1 \text { jam } \\
\text { atau lebih dan } \\
\text { perlu ketelitian } \\
\text { terutama desain } \\
\text { yang rumit }\end{array}$ & $\begin{array}{c}\text { Dilakukan } \\
\text { secara otomatis } \\
\text { saat pembuatan } \\
\text { desain tenun } \\
\text { (No.1) }\end{array}$ \\
\hline 3 & $\begin{array}{l}\text { Pemasangan } \\
\text { kartu dobby } \\
\text { pada ATBM }\end{array}$ & $\begin{array}{c}\text { Dilakukan } \\
\text { selama } 30 \\
\text { menit-1jam, } \\
\text { atau tergantung } \\
\text { dari panjangnya } \\
\text { kartu dobby }\end{array}$ & $\begin{array}{c}\text { Dilakukan } \\
\text { secara } \\
\text { elektronik }\end{array}$ \\
\hline 4 & $\begin{array}{l}\text { Sistem } \\
\text { penguluran } \\
\text { benang lusi }\end{array}$ & Manual & Elektronik \\
\hline 5 & $\begin{array}{l}\text { Sistem } \\
\text { penggulungan } \\
\text { kain }\end{array}$ & Manual & Elektronik \\
\hline 6 & $\begin{array}{l}\text { Sistem } \\
\text { peluncuran } \\
\text { benang pakan }\end{array}$ & Manual & Manual \\
\hline 7 & $\begin{array}{l}\text { Sistem } \\
\text { pengetekan }\end{array}$ & Manual & Manual \\
\hline 8 & $\begin{array}{l}\text { Sistem } \\
\text { pembukaan } \\
\text { mulut lusi }\end{array}$ & $\begin{array}{l}\text { Injakan } \\
\text { mekanik }\end{array}$ & $\begin{array}{c}\text { Injakan } \\
\text { elektronik }\end{array}$ \\
\hline
\end{tabular}

Sistem pengatur tegangan benang lusi pada ATBM umumnya ialah menggunakan tali dan batang kayu untuk mengatur putaran beam benang lusi. Sistem penggulungan kain menggunakan roda gigi rachet. Pada ATBM dobbyelektronik sistem penguiuran benang lusi dan penggulungan kain diubah secara elektronik yaitu dengan penambahan motor pada bagian beam benang lusi dan rol kain. Sehingga penenun dengan mudah dapat mengatur tegangan benang lusi hanya dengan menekan tombol penguluran benang lusi dan penggulungan kain.

Dengan modifikasi pada bagian desain tenun dan gerakan pertenunan pada ATBM, hal ini terbukti memudahkan penenun. Hal ini juga berpengaruh terhadap kinerja operator tenun terutama dalam hal produktivitas. Kinerja mesin yang lebih optimal berpengaruh terhadap tenaga operator tenun yang digunakan lebih rendah jika dibandingkan dengan ATBM dobby mekanik.

\section{KESIMPULAN}

Dari kegiatan yang telah dilakukan, pada prinsipnya ATBM Dobby Elektronik tersebut dapat berjalan dengan baik. Beberapa hal yang dapat disimpulkan adalah.

1. ATBM yang dihasilkan memiliki kapasitas 8 kamran, penguluran lusi dan penggulungan kain secara elektronik, dan 1 unit software desain.

2. Kualitas kain hasil ATBM dobbyelektronik telah diuji sesuai dengan SNI 0051:2008, kain tenun untuk kemeja. Hasil uji menunjukkan kualitas kain ATBM berada diatas persyaratan minimal SNI 0051:2008.

3. Parameter pengujian ATBM dobby elektronik ialah pembentukan mulut lusi termasuk juga besarnya tegangan lusi, peluncuran pakan, penguluran benang lusi, penggulungan kain, dan komunikasi antara software desain dan ATBM.

4. Parameter pembukaan mulut lusi dan komunikasi antara software desain dan ATBM, menjadi 2 parameter yang sering menyebabkan terjadinya kesalahan(error) pada ATBM.

5. Solusi untuk mengurangi berhenti mesin karena masalah pembukaan mulut lusi yang tidak rata yaitu dengan mengatur ketinggian simpul tali kamran. Sedangkan untuk mengurangi berhenti mesin karena masalah komunikasi antara software desain dan ATBM yaitu dengan membuat standar prosedur kerja ATBM dobby elektronik dan memeriksa kondisi sikring (fuse) dan relay.

\section{PUSTAKA}

1. Intani T, Ria. Tenun Gedogan Dermayon. Patanjala Vol. 2, No. 1 Maret : 35-47 (2010).

2. Wartiono, Totok., Wiyono., Musabbikhah. Inovasi ATBM dengan Pengendali PLC (Programmable Logic Control) Sebagai Alat Tenun Alternatif. Prosiding Seminar Nasional Teknoin 2008 Bidang Teknik Elektro(2008).

3. Adanur, Sabit. Handbook of Weaving. Pennsylvania : Technomic Publishing Co. Inc. (2000). 
4. Ali Ramdani, Moch., Latief, Mohammad. Sistem Kendali Listrik Berbasis Android. Jurnal Informasi Vol. VIII No. 1 Februari (2016).

5. Kurniawan, Wahyu Dwi., Budijono, Agung Prijo. Pengembangan Perangkat Pembelajaran Mekatronika Berbasis Komputer Pokok Bahasan Programmable Logic Controller Berorientasi Pada Pembelajaran Langsung. Jurnal Pendidikan Tinggi dan Kejuruan, Vol. 1 No. 3 (2013).

6. Yin, Honghuan., Yu, Hongbin., Jin, Yonglian., Li, Xuekui.Comprehensive Performance Test of Dobby and Analysis System. International Conference on Mechatronics Engineering and Information Technology (ICMEIT) , 343348(2016).

7. Farhan, Khalid., Ahmad, Tasweer., Khalid, Ali.Framework for Automated Dobby Based Fabric Design System. International Journal of Scientific and Engineering Research Vol. 5, 879-885(2014).

8. Laksono, Heru Dibyo., Sonni, M. Nasir. Perancangan dan Implementasi Arus Lebih Sesaat Berbasis Microcontroller. Gematek Jurnal Teknik Komputer, Vol. 9 No. 2, September (2007).

9. Alamsyah., Amir, Ardi., Faisal, Muhammad Nur.Perancangan dan Penerapan Sistem Kontrol Peralatan Elektronik Jarak Jauh Berbasis Web. Jurnal Mekanikal Vol. 6 No. 2, 577-584(2015).

10. Castelli, Giovanni., Maietta, Salvatore., Sigrisi, Giuseppe., Slaviero, Ivo Matteo.Weaving : References Books of Textile Technologies, Milan : Fondazione ACIMIT (2000).

11. Hadjib, Nurwati., Muslich, Mohammad., Sumarni, Ginuk. Sifat Fisis Kayu Jati Super dan Jati Lokal dari Beberapa Daerah
Penanaman. Jurnal Penelitian Hasil Hutan Vol. 24 No. 4, 359-369 (2006).

12. Doi, Hiroki., Shioyama,Takuto., Fujikawa , Fuyuki., Serizawa, Yoshizumi.Study on Delay Time Evaluation for Carrier Relay System Using IP Communications Technology. Journal of International Council on Electrical Engineering, 3:3, 234-239 (2013).

13. Ball, Alex. Preserving Computer-Aided Design $(C A D)$. Great Britain : Digital Preservation Coalition (2013).

14. Song, Chang-Woo., Lee, Seung-Yop.Design of a Solenoid Actuator with a Magnetic Plunger forMiniaturized Segment Robots. Applied Science, 5, 595-607 (2015).

15. Badan Standardisasi Nasional.SNI 0051:2008 Kain Tenun untuk Kemeja, Jakarta : Badan Standardisasi Nasional, (2007).

16. Soekarso, R. Pengantar Ilmu Anyaman Tekstil. Bandung : Tarate (1974).

17. Suantara, Dermawati., Siregar, Yusniar., Moeliono, Moekarto.Karakteristik Kain ATBM Dobby Hasil Pengembangan Motif Batik Khas Kota Bandung Sebagai Motif Tenun Ikat Untuk Kain Kemeja.Arena Tekstil Vol. 31 No. 1 : 1722 (2016).

18. Kim, Hwan Kuk., Chun, Du Hwan., Kim, Jung Han. A Study on Correlation between Warp Tension and Weaving Condition. Fibers and Polymers, Vol. 14, No. 12 (2013).

19. Dubrovski, Polona Dobnik. Woven Fabric Engineering. Rijeka : Sciyo (2010).

20. Fernando, Eask., Kuruppu, R. U. Tension Variation in Sectional Warping, Part I : Mathematical Modelling of Yarn Tension in a Creel. International Journal of Engineering and Advanced Technology, Vol. 4, Issue 3 (2015). 